\title{
A study of various cesarean section techniques at a government tertiary care centre: Misgav Ladach cesarean section versus Pfannenstiel cesarean section
}

\author{
Medha Kanani* \\ Department of Obstetrics and Gynecology, Sir T General Hospital and Government Medical College, Bhavnagar, \\ Gujarat, India
}

Received: 20 May 2017

Revised: 01 June 2017

Accepted: 20 June 2017

\author{
*Correspondence: \\ Dr. Medha Kanani, \\ E-mail: kananimedha@gmail.com
}

Copyright: $\odot$ the author(s), publisher and licensee Medip Academy. This is an open-access article distributed under the terms of the Creative Commons Attribution Non-Commercial License, which permits unrestricted non-commercial use, distribution, and reproduction in any medium, provided the original work is properly cited.

\section{ABSTRACT}

Background: It is important to examine every step in any surgery to identify and evaluate its imortance, necessity and purpose with a view to find its better alternatives if they can be found at all. The most appropriate surgical procedure is the one which takes minimum time to be complete, simplest to perform, causing least damage and least complication for the patient. Present study was undertaken to assess the benefits of the Misgav Ladach cesarean section technique in comparison to the conventional Pfannenstiel technique in the tertiary care hospital and evaluate the operative parameters like efficacy, safety, duration of surgery, blood loss, need for suture material, post-operative pain and post-operative stay in hospital.

Methods: All the women posted for emergency cesarean section in the Obstetrics OT at Sir T Hospital, Bhavnagar, Gujarat were included in this study. Some of the common indications at our hospital for cesarean section were fetal distress, cephalopelvic disproportion, failure of progress of labour, breech presentation, previous cesarean section and failed induction. Informed consent was taken. All the patients were randomly allocated to two groups with 50 women in each group. Group 1 Pfannenstiel incision and Group 2 Misgav Ladach.

Results: The duration of surgery, blood loss and post-operative pain were significantly less in the Misgav Ladach group $(\mathrm{P}<0.001)$.

Conclusions: Misgav Ladach technique of cesarean section has many advantages and should be used routinely.

Keywords: Cesarean section, Misgav Ladach, Pfannenstiel

\section{INTRODUCTION}

All the surgical procedures have their own way and method of being performed, every method has its own reason and purpose, meaning and history behind its evolution. It is important to examine every step in any surgery to identify and evaluate its imortance, necessity and purpose with a view to find its better alternatives if they can be found at all. The most appropriate surgical procedure is the one which takes minimum time to be complete, simplest to perform, causing least damage and least complication for the patient. Such procedure should be continuously looked and searched for in the view of achieving better health of the patients.

In today's world there is a continous search for better and more satisfactory techniques for cesarean section. ${ }^{1}$ The technique should be safe, of short duration, simple, have 
low cost, carry less post-operative morbidity and give a strong scar. ${ }^{1}$

Timonen et al found that in Pfannenstiel cesarean section, lag time form incision to delivery was 8-10 minutes. ${ }^{1,2}$ On the other hand, Misgav Ladach cesarean section offers the benefit of the incision to delivery interval being 4 minutes or less. ${ }^{1,2}$ Therefore it can be beneficial in the cesarean sections for fetal distress which is the most common indication for cesarean section. ${ }^{2,3}$

Sharp dissection is used very less therefore the blood loss can be minimal. Uterus is exteriorized which makes suturing easier. Uterine incision is closed in a single layer to give greater strength to the $\operatorname{scar}^{4}$ and it reduces the intra-operative time and the cost of surgery. ${ }^{1}$ At the end, the most concerned thing is post-operative pain to the patient which is also reduced in the Misgav Ladach technique $^{1}$ because suturing the peritoneum is superfluous, since it heals rapidly without suturing. ${ }^{5,6}$

Present study was undertaken to assess the benefits of the Misgav Ladach cesarean section technique in comparison to the conventional Pfannenstiel technique in the tertiary care hospital and evaluate the operative parameters like efficacy, safety, duration of surgery, blood loss, need for suture material, post-operative pain and post-operative stay in hospital.

\section{METHODS}

All the women posted for emergency cesarean section in the Obstetrics OT at Sir T Hospital, Bhavnagar, Gujarat were included in this study. Some of the common indications at our hospital for cesarean section were fetal distress, cephalopelvic disproportion, failure of progress of labour, breech presentation, previous cesarean section and failed induction. Informed consent was taken. All the patients were randomly allocated to two groups with 50 women in each group. Group 1 Pfannenstiel incision and Group 2 Misgav Ladach. The differences in the two procedures are below.

\section{Exclusion criteria}

- Women with more than one previous cesarean section, previous abdominal surgery

- Women with bleeding disorders

- Women taking anticoagulant therapy

- Women with twin pregnancy, placenta previa, abruptio placenta and ruptured uterus.

All the cesarean sections in this study were performed under spinal anesthesia, by the consultant. The allocated method of surgery was decided by random numbers drawn by the OT nurse just before surgery. The OT nurse measured the operation time, while the blood loss was jointly estimated by the surgeon and the OT nurse from the suction bottle and the mops used. The OT nurse even counted the suture material used.
Normal pre- and postoperative care for cesarean section were adhered to during whole study period and were similar to both group patients. Intravenous fluids were given for 12 hours after which oral fluids were started according to the tolerance of women. Ambulation was encouraged after 24 hours of the surgery to all.

$1 \mathrm{gm}$ Cefalexin intravenously every 12 hours and $100 \mathrm{ml}$ Metronidazole every 8 hours for 48 hours postoperatively were given to all. Then from $3^{\text {rd }}$ postoperative day oral antibiotics were started and continued for 5 more days. This is the prophylactic antibiotic protocol at our instituition as the rural patients are more here who are malnorished, anemic and with poor immunity most of the time.

Injection diclofenac sodium was given intramuscularly to all patients every 8 hours for 2 postoperative days. Thereafter oral pain killer tablets were given every 8 hours for 3 more days.

\section{RESULTS}

Table 2 gives the demographic data of two groups. All women were at term.

Table 3 shows the duration of surgery in two groups. The shortest duration of surgery was 17 minutes 30 seconds in Group 1 and 12 minutes 46 seconds in Group 2 $(\mathrm{p}<0.001)$.

There was a statistically significant decrease in blood loss in Group 2 as compared to Group $1(\mathrm{p}=0.001)$. Almost $50 \%$ of the women in Group 2 has a blood loss of $<250$ $\mathrm{ml}$ as compared to Group 1 (Table 3).

There were two patients in each group with blood loss of more than $800 \mathrm{ml}$ and two had blood transfusion in Group 1 and one in Group 2. The patients in Group 1 had a mean blood loss that was more than double that of Group 2. This is statisfically significant $(\mathrm{p}<0.001)$ (Table 2).

Table 3 shows the duration of surgery in two groups. The shortest duration of surgery was 17 minutes 30 seconds in Group 1 and 12 minutes 46 seconds in Group 2 $(\mathrm{p}<0.001)$. There was a statistically significant decrease in blood loss in Group 2 as compared to Group 1 $(\mathrm{p}=0.001)$.

Almost $50 \%$ of the women in Group 2 has a blood loss of $<250 \mathrm{ml}$ as compared to Group 1 (Table 3).

There were two patients in each group with blood loss of more than $800 \mathrm{ml}$ and two had blood transfusion in Group 1 and one in Group 2. The patients in Group 1 had a mean blood loss that was more than double that of Group 2. This is statisfically significant $(\mathrm{p}<0.001)$ (Table 2). 
Table 1: Comparison between two methods of emergency cesarean section.

\begin{tabular}{|lll|}
\hline Steps & Group 1 (Pfannenstiel) $n=50$ & Group 2 (Misgav Ladach) $n=50$ \\
\hline Sype of skin incision & Pfannenstiel & Joel Cohen \\
\hline Rectus sheath & Cut with scissors & Digital separation (with fingers) \\
\hline Rectus muscle & Cut with scissors & Separated by fingers and retracted \\
\hline $\begin{array}{l}\text { Peritoneum } \\
\text { Uterovesical fold of } \\
\text { peritoneum }\end{array}$ & Cut with scissors & Opened by stretching \\
\hline Uterine incision & $\begin{array}{l}\text { Cut with scissors after separating it from lower } \\
\text { uterine segment }\end{array}$ & Digital separation \\
\hline $\begin{array}{l}\text { Uterus sutured in how many } \\
\text { layer }\end{array}$ & $\begin{array}{l}\text { Cut with scissors } \\
\text { Two layers with continous interlocking stiches }\end{array}$ & One layer with continuous interlocking \\
\hline $\begin{array}{l}\text { in each layer, second layer burrying the stiches } \\
\text { of first layer }\end{array}$ & \\
\hline Rectus muscle sutured & Not sutured & Not sutured \\
\hline $\begin{array}{l}\text { Rectus sheath sutured } \\
\text { Skin sutured with vicryl no-1 } \\
\text { suture }\end{array}$ & With continuous stitches & No \\
\hline
\end{tabular}

Table 2: Demographic data.

\begin{tabular}{|lll|}
\hline & $\begin{array}{l}\text { Group 1 } \\
\text { (Pfannenstiel) } \\
\text { n=50 }\end{array}$ & $\begin{array}{l}\text { Group 2 } \\
\text { (Misgav } \\
\text { Ladach) n=50 }\end{array}$ \\
\hline Average age (years) & 23.56 & 23.75 \\
\hline $\begin{array}{l}\text { Primigravida } \\
\text { Multigravida }\end{array}$ & 29 & 32 \\
\hline $\begin{array}{l}\text { Average } \\
\text { gestational age } \\
\text { (weeks) }\end{array}$ & 38.84 & 18 \\
\hline $\begin{array}{l}\text { Weight of the } \\
\text { baby (gm) }\end{array}$ & 2950 & 39.15 \\
\hline $\begin{array}{l}\text { Mean apgar score } \\
\text { at 1 min }\end{array}$ & 8.3 & 2975 \\
\hline $\begin{array}{l}\text { Mean apgar score } \\
\text { at 5 min }\end{array}$ & 9.6 & 8.5 \\
\hline
\end{tabular}

Table 3: Sutures used (Vicryl no-1) and duration of surgery.

\begin{tabular}{|c|c|c|c|}
\hline $\begin{array}{l}\text { No. of } \\
\text { sutures } \\
\text { used }\end{array}$ & $\begin{array}{l}\text { Group } 1 \\
\text { (Pfannenstirl) } \\
\mathbf{n}=\mathbf{5 0}\end{array}$ & $\begin{array}{l}\text { Group } 2 \\
\text { (Misgav } \\
\text { Ladach) } n=50\end{array}$ & $\begin{array}{l}X^{2} \\
\text { test }\end{array}$ \\
\hline $\begin{array}{l}\text { Only one } \\
\text { suture used }\end{array}$ & 12 & 48 & \multirow[t]{2}{*}{$\begin{array}{l}\mathrm{P} \\
<0.001\end{array}$} \\
\hline $\begin{array}{l}\text { Two sutures } \\
\text { used }\end{array}$ & 36 & 2 & \\
\hline $\begin{array}{l}\text { More than } \\
\text { two sutures } \\
\text { used }\end{array}$ & 2 & 0 & \\
\hline $\begin{array}{l}\text { Mean } \\
\text { duration of } \\
\text { surgery time } \\
(\text { min })\end{array}$ & $28.34 \pm 5.25$ & $18.15 \pm 3.78$ & $\begin{array}{l}\mathrm{P} \\
<0.001\end{array}$ \\
\hline
\end{tabular}

Group 1 had double layer closure of the uterine incision and Group 2 had a single layer uteine incision closure, which is the reason for statisfically more siginificant suture material used in group 1 (Table 3 ). There is a continuing follow up of these women till subsequent pregnancy to see the difference in obstetric outcome including operative intervention.

Table 4: Blood loss (ml).

\begin{tabular}{|lll|}
$\begin{array}{l}\text { Blood } \\
\text { loss }(\mathrm{ml})\end{array}$ & $\begin{array}{l}\text { Group } 1 \\
\text { (Pfannenstiel) } n=50\end{array}$ & $\begin{array}{l}\text { Group 2 (Misgav } \\
\text { Ladach) } n=50\end{array}$ \\
\hline$<250$ & 5 & 24 \\
\hline $250-499$ & 26 & 20 \\
\hline $500-749$ & 14 & 4 \\
\hline $750-$ & 4 & 1 \\
1000 & 1 & 1 \\
\hline$>1000$ & 1 & $294 \pm 200$ \\
\hline Mean & $455.6 \pm 202$ & \\
\hline
\end{tabular}

Postoperatively assessment of pain was done using the visual analogue scale on 2, 3, 4 and 5th day. It was found that the pain was significantly less $(\mathrm{p}<0.001)$ in Group 2 compared to that in Group 1 (Table 5). This was reflected by the decreased use of oral analgesics in Group 2 .

\section{DISCUSSION}

Today in the era of increasing rate of cesarean section one must evaluate the means of reducing it. The most important thing is to reduce the duration of surgery so as reducing the duration of anesthesia therefore reducing the morbidity. In cases like fetal distress reduction in the duration of surgery upto $30 \%$ is important. Shorter induction to delivery time during cesarean secion reduces rate of infection and also the perinatal morbidity. The originator of Misgav Ladach method of cesarean section at General Hospital at Jerusalem compared it to a Pfannenstiel cesarean section. ${ }^{7}$ 
Table 5: Pain score on $2^{\text {nd }}, 3^{\text {rd }}$ and $5^{\text {th }}$ day.

\begin{tabular}{|c|c|c|c|c|c|c|}
\hline \multirow{2}{*}{ Pain Score } & \multicolumn{2}{|l|}{ Day-2 } & \multicolumn{2}{|l|}{ Day-3 } & \multicolumn{2}{|l|}{ Day-5 } \\
\hline & Group 1 & Group 2 & Group 1 & Group 2 & Group 1 & Group 2 \\
\hline 0 (No pain) & 0 & 3 & 2 & 3 & 18 & 32 \\
\hline 1 & 0 & 0 & 1 & 20 & 25 & 16 \\
\hline 2 & 1 & 1 & 16 & 10 & 5 & 1 \\
\hline 3 & 0 & 8 & 10 & 10 & 1 & 0 \\
\hline 4 & 1 & 3 & 6 & 5 & 0 & 0 \\
\hline 5 & 3 & 28 & 11 & 2 & 0 & 0 \\
\hline 6 & 1 & 3 & 2 & 0 & 0 & 0 \\
\hline 7 & 12 & 3 & 2 & 0 & 0 & 0 \\
\hline 8 & 13 & 1 & 0 & 0 & 0 & 0 \\
\hline 9 & 16 & 0 & 0 & 0 & 0 & 0 \\
\hline $\begin{array}{l}10 \text { (Maximum } \\
\text { pain) }\end{array}$ & 3 & 0 & 0 & 0 & 0 & 0 \\
\hline $\mathrm{X}^{2}$ test & $\mathrm{P}=0.0001$ & & $\mathrm{P}=0.0001$ & & $\mathrm{P}=0.0001$ & \\
\hline
\end{tabular}

Women with previous cesarean section was included in the study and 50 to $70 \%$ were operated under epidural anesthesia. Main findings were reduction in operating time, reduced incidence of post-operative febrile morbidity and fewer adhesions at subsequent cesarean section. In this study, the mean operative duration of Group 1 was $28.34 \pm 5.25$ and of Group 2 was $18.15 \pm 3.78$ (Table 3) $\mathrm{P}<0.001$.

Amount of blood loss was decreased in Group 2 as compared to Group 1 because of less sharp dissection. Here the mean blood loss in Group 2 was $294 \pm 200 \mathrm{ml}$ in compared to Group 1 which was $455.6 \pm 202 \mathrm{~mL}$.

$(\mathrm{P}<0.001)$ Decreased operation time may also influence the amount of bleeding during surgery. This reduced blood loss during Misgav Ladach technique of cesarean section has also been reported by other various studies.

In the Group 2 the fewer suture materials were used in comparisom to Group 1 in this study. Due to shorter operation time, there are many other economic benefits. Here there was not much statistical difference in intraamd post-operatice complications between the two groups. This reduced incidence of infection may be due to our prophylactic antibiotic coverage to all the patients.

At our institute, early ambulation was encouraged enthusiastically and almost all the patients were out of bed on the next day of cesarean section. Nill by mouth state was released usually after 12 hours with water and clear fluids.

Women who underwent Misgav Ladach cesarean technique needed much less help in ambulation due to less pain. In this study, no negative effects of Misgav Ladach technique of cesarean section were noted. ${ }^{8-11}$

\section{CONCLUSION}

We strongly recommend that this technique should be used in all the centres wherever feasible. It is suitable for both emergency and elective surgeries. Waiting for more studies to prove the efficacy and safety of single layer uterine closure, especially in relation to long term outcomes, we recommend a double-layer uterine closure or in alternative an unlocked single layer. Reduction in post-operative pain, reduced blood loss and speedy recovery enable mothers to take better care of their babies in immediate post-operative period and help developing mother-baby bonding better. These all things overall reduce the maternal and perinatal morbidity. Concluding, to identify the safest and most appropriate surgical technique for both mother and newborn in order to minimize morbidity, postoperative pain, ensuring the best possible short and long-term outcomes for both mother and child, minimizing the risk of cesarean scar defects and uterine rupture, and allowing vaginal delivery in the next pregnancy is the main goal of future obstetrics and the first step to pragmatically reduce the rate of cesarean sections. The ultimate aim of the obstetrician of providing good health to the mother and the baby is then served by it.

\section{Funding: No funding sources}

Conflict of interest: None declared

Ethical approval: The study was approved by the Institutional Ethics Committee

\section{REFERENCES}

1. Chitra K, Nirmala AP, Gayetri R, Jayanthi AV, Shanthi S. Misgav Ladach Cesarean Section vs Pfannenstiel Cesarean Section. J Obstet Gynecol India. 2004;54(5):473-7. 
2. Timonen S, Castren O, Kivalo I. Caesarean section. Low transverse (Pfannenstiel) or low midline incision? Ann Chir Gynaecol Fenn. 1969;59:173-6.

3. Stark M. Technique of Caesarean section: the Misgav - Ladach method. In: Popkin DR, Peddle LJ. eds. Women's health today. perspectives on current research and clinical practice. Proceedings of the 14th World Congress on Gynecology and Obstetrics. London. Partheneon. 81-5.

4. Tucker JM, Hauth JC, Hodgkins P. Trial of labour after a one or two layer closure of a low transverse uterine incision. Am J Obstet Gynecol. 1993;168:545-6.

5. Chamberlain G. Caesarean Section. In Chamberlain G, Steer P, editors. Turnbull's Obstetrics, $3^{\text {rd }}$ ed. London: Harcourt Publishers;2001:612.

6. Heys SD, Goughd, Steele RJ. The Gastrointestinnal system: The peritoneum. In Eremin O, editor. The scientific and clinical basis of surgical practice. 1st ed. Nottingham Oxford University Press;2001:246.

7. Sjoholm L, Holmgren G. The Misgav Ladach method of cesarean section: evolved by Joel Cohen and Michael Stark in Jerusalem. Trop Doct. 1996;26:160
8. National Collaborating Centre for Women's and children's health (UK) Caesarean section. RCOG press; London:2011.

9. Roberge S, Chaillet N, Boutin A, Moore L, Jastrow $\mathrm{N}$, Brassard N, et al. Single-versus double-layer closure of the hysterotomy incision during cesarean delivery and risk of uterine rupture. Int $\mathbf{J}$ Gynecol Obstet. 2011;115(1):5-10.

10. Glavind J, Madsen LD, Uldbierg N, Dueholm M. Ultrasound evaluation of Cesarean scar after singleand double-layer uterotomy closure: a cohort study. Ultrasoun Obstet Gynecol. 2013;42:207-12.

11. Bujold E, Goyet M, Marcoux S, Brassard N, Cormier $\mathrm{B}$, Hamilton E, et al. The role of uterine closure in the risk of uterine rupture. Obstet Gynecol. 2010;116(1):43-50.

Cite this article as: Kanani M. A study of various cesarean section techniques at a government tertiary care centre: Misgav Ladach cesarean section versus Pfannenstiel cesarean section. Int J Reprod Contracept Obstet Gynecol 2017;6:3449-53. 